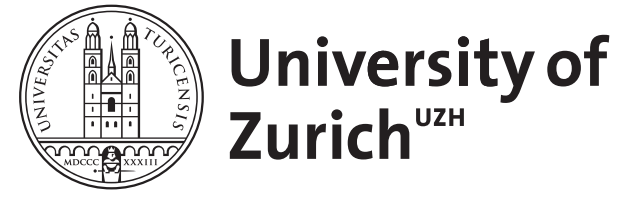

\title{
Metabolic disease resources
}

Dobay, Maria Pamela ; Dobay, Akos

Posted at the Zurich Open Repository and Archive, University of Zurich ZORA URL: https://doi.org/10.5167/uzh-78548

Book Section

Originally published at:

Dobay, Maria Pamela; Dobay, Akos (2013). Metabolic disease resources. In: Dubitzky, Werner; Wolkenhauer, Olaf; Cho, Kwang-Hyuan; Yokota, Hiroki. Encyclopedia of Systems Biology. Deutschland: Springer Verlag, 2367 p. 


\section{Metabolic disease resources}

Maria Pamela Dobay, Department of Physics, Ludwig-Maximilians University, Munich, Germany, maria.pamela.david@physik.uni-muenchen.de Akos Dobay, Institute of Evolutionary Biology and Environmental Studies, University of Zurich, Switzerland

\section{Definition}

Metabolic disease resources include several databases that provide information on the causes, clinical manifestations, as well as diagnostic and genetic indicators of metabolic diseases. These resources are often extensively cross-linked to databases containing gene, protein and metabolite information, and have been used in developing systems for predicting metabolite level changes, as well as predicting biomedical data given a metabolic disorder as an input (Chen et al. 2006), among other examples. These databases have also been used for establishing disease models from orthologous phenotypes (McGary et al. 2010) and phenotype categorization (Sadreyev et al. 2009).

\section{Characteristics}

This section deals with the different types of resources available, grouped according to the primary focus of the database. Databases that are widely used in metabolomics studies, but that are not directly related to disease, such as the Kyoto Encyclopedia of Genes and Genomes (KEGG), are discussed under General metabolic network databases.

\section{Genetic metabolic disease resources}

\section{Online Mendelian Inheritance in Man (OMIM)}

OMIM (http://www.omim.org/, http://www.ncbi.nlm.nih.gov/omim, Amberger et al. 2009, Hamosh et al. 2005) is a comprehensive database on human genes and genetic disorders, including genetic metabolic disorders. Its particular focus is on the relationship between genetic variation and the corresponding phenotype. It is a continuation of Dr. Victor McKusick's Mendelian Inheritance in Man (MIM), a compilation of mendelian traits and disorders initiated in the 1960s, and published between 1966 and 1998 as twelve book editions. There are currently two versions of OMIM. One is currently hosted and integrated with the National Center for Biotechnology Information (NCBI) database suites, while another is hosted directly at Johns Hopkins University School of Medicine. 
All OMIM contents are authored and edited at the McKusick-Nathans Institute of Genetic Medicine, Johns Hopkins University School of Medicine under Dr. Ada Hamosh. The OMIM version at NCBI has not been updated since February 22, 2011 pending an agreement between Johns Hopkins University and the National Institutes of Health. As of May 2011, OMIM contains a total of more than 20500 entries.

OMIM entries are identified by unique six-digit identifier (MIM number prefixes) that indicate whether a disease is X-linked, Y-linked or autosomal. Symbol prefixes are also appended to these MIM number prefixes to indicate the availability of genetic and phenotypic information of an entry (Table 1).

Table 1. Numbering system of the OMIM database

\begin{tabular}{|c|l|}
\hline Number/symbol prefix & \\
\hline 1 & $\begin{array}{l}\text { Autosomal loci or phenotypes (entries } \\
\text { created before 15 May 1994) }\end{array}$ \\
\hline 2 & $\begin{array}{l}\text { Autosomal loci or phenotypes (entries } \\
\text { created before 15 May 1994) }\end{array}$ \\
\hline 3 & X-linked loci or phenotypes \\
\hline 4 & Y-linked loci or phenotypes \\
\hline 5 & Mitochondrial loci or phenotypes \\
\hline 6 & $\begin{array}{l}\text { Autosomal loci or phenotypes (entries } \\
\text { created after 15 May 1994) }\end{array}$ \\
\hline$*$ & Causative gene has a known sequence \\
\hline$\#$ & $\begin{array}{l}\text { Descriptive entry (phenotype); may not } \\
\text { represent a unique locus }\end{array}$ \\
\hline+ & $\begin{array}{l}\text { Entry contains both a gene description } \\
\text { and a phenotype }\end{array}$ \\
\hline$\%$ & $\begin{array}{l}\text { Confirmed Mendelian phenotype whose } \\
\text { molecular basis is not known }\end{array}$ \\
\hline$\wedge$ & Entry removed \\
\hline &
\end{tabular}

OMIM entries can be accessed using a conventional text-based search. Under the advance search options, entries can be searched according to the MIM number prefix, the chromosome number, or the creation date of a record. In www.omim.org, it is possible to search entries according to the clinical synopsis. Each OMIM entry may contain the following information:

1. Disease description

2. Nomenclature

3. Clinical features

4. Biochemical features

5. Inheritance

6. Diagnosis 
7. Clinical management

8. Pathogenesis

9. Mapping

10. Molecular genetics

11. Heterogeneity

12. Existing animal models of the disease

All entries contain hyperlinks to the relevant references in PubMed associated with each finding. Resources in OMIM include the OMIM Morbid Map, which lists disease genes organized by disease, and the OMIM Gene Map, which maps disease genes to chromosomes.

\section{Metabolic disease pathway resource}

\section{Small molecule pathway database (SMPDB)}

SMPDB (http://www.smpdb.ca/, Frolkis et al. 2010) is an interactive, visual database that focuses on small molecule pathways in humans. SMPDB includes metabolic, disease, metabolic signaling and drug action pathways. In all these pathways, locations of reactions, from the organ to the subcellular level, are indicated. Nonmetabolite pathway components such as proteins, are hyperlinked to UniProt, whereas small molecule components, including the metabolites as well as drugs, are hyperlinked to the human metabolome database (see HMDB under Specialized metabolic component databases) and DrugBank, respectively. The SMPDB is part of the HMDB suite of databases.

\section{Diagnosis and treatment support resources}

Metabolic \& Genetic Information Information Center (MetaGene) and Rare Metabolic Diseases Database (RAMEDIS)

MetaGene (http://www.metagene.de/index.html, Trefz et al. 2008) is a repository for comprehensive information on around 432 genetic metabolic diseases, including information on differential diagnoses, clinical and laboratory findings, as well as literature. It is designed for use by health care professionals as a tool to support diagnosis and treatment of patients with rare metabolic disorders. Database entries are searchable on the basis of disease name, symptoms, laboratory test parameters, patient information (see RAMEDIS) and clinical study author. Cross-references to genetic information and related genetic tests via OMIM and GeneTests (http://www.ncbi.nlm.nih.gov/projects/GeneTests/static/about/whatis/mission.shtml), as well as information on clinical symptoms and treatment, are provided for each disease entry.

RAMEDIS (https://www.imbio.de/stable/php/ramedis/htdocs/eng/index.php, Töpel et al. 2006) is a partner database where detailed patient information on rare metabolic 
diseases are collected. As opposed to MetaGene, information in RAMEDIS includes patient and diagnostic information, in addition to case-specific symptoms, laboratory findings, therapy and molecular data. RAMEDIS has a feature that permits cooperative studies. RAMEDIS currently contains records from 807 patients representing 93 genetic metabolic diseases.

\section{OrphaNet}

Orphanet (http://www.orpha.net/consor/cgi-bin/index.php?lng=EN, Nabarette et al. 2006) contains information on rare diseases and orphan drugs, including those associated with metabolic diseases. It is primarily geared towards the improvement of diagnosis, care and treatment of patients with rare diseases. Its features include an inventory and classification of rare diseases; an inventory of orphan drugs, including those currently under development, and an assistance-to-diagnosis tool that permits users to search entries based on disease symptoms.

\section{Cross-reference}

General metabolic network databases

Specialized metabolic component databases

\section{References}

Amberger J, Bocchini CA, Scott AF, Hamosh A (2009) McKusick's Online Mendelian Inheritance in Man (OMIM®). Nucleic Acids Research 37:D793-D796.

Trefz F, Scheible D, Götz H, Töpel T, Hofestädt R, Frauendienst-Egger G. METAGENE and RAMEDIS: databases for metabolic diseases and patients with inborn errors on metabolism (2008) Journal of Inherited Metabolic Disease 31:289.

Frolkis A, Knox C, Lim E, Jewison T, Law V, Hau DD, Liu P, Gautam B, S Ly, A. C Guo, J Xia, Y Liang, S Shrivastava, D. S Wishart (2010) SMPDB: The Small Molecule Pathway Database. Nucleic Acids Research 38:D480-487

Hamosh A, Scott AF, Amberger JS, Bocchini CA, McKusick VA (2005) Online Mendelian Inheritance in Man (OMIM), a knowledgebase of human genes and genetic disorders. Nucleic Acids Research 33:D514-D516

McGary KL, Park TJ, Woods JO, Cha HJ, Wallingford JB, Marcotte EM (2010) Systematic discovery of nonobvious human disease models through orthologous phenotypes. Proc. Natl. Acad. Sci. 107:6544-6549 
Nabarette H, Oziel D, Urbero B, Maxime N, Aymé S (2006) Utilisation d'un annuaire des services spécialisés et orientation dans le système de soins: l'exemple d'Orphanet dans les maladies rares. Revue d'Epidémiologie et de Santé Publique 54:41-53

Sadreyev RI, Feramisco JD, Tsao H, Grishin NV (2009) Phenotypic categorization of genetic skin diseases reveals new relations between phenotypes, genes and pathways. Bioinformatics 25: 2891-2896

Töpel T, Hofestädt R, Scheible D, Trefz F (2006) RAMEDIS: The rare metabolic disease database. Applied Bioinformatics 5:115-118 